\title{
Urban air quality evaluation over Kut city using field survey and Geomatic techniques
}

\author{
Zainab Mohammed ${ }^{1}$, Abdulrazzak. Ziboon ${ }^{1, *},{\text { Ali } \text { Kamal }^{1} \text { and Mahdi Alfaraj }}^{2}$ \\ ${ }^{1}$ Building and Construction Engineering Department, University of Technology, Baghdad, Iraq \\ ${ }^{2}$ Architectural Engineering Department, University of Technology, Baghdad, Iraq
}

\begin{abstract}
Air pollution is caused by various sources such as cars exhaust, energy sources, petrol stations, industrial activities, and other sources. The aim of this study was to measure some air pollutants gases, representing the results by Arc GIS maps over AL-Kut city and finding the ways for reducing them. Twenty samples have been taken using Global Positioning System (GPS) for measuring the main air pollutants (sulfur dioxide $\left(\mathrm{SO}_{2}\right)$, nitrogen dioxide $\left(\mathrm{NO}_{2}\right)$, carbon monoxide $(\mathrm{CO})$, ozone $\left(\mathrm{O}_{3}\right)$, total suspended particle (TSP), and particulate matters (PMs). The measurements were carried out by several specialized portable equipment at afive months starting from November 2015 to March 2016. The distribution maps resulted from ArcGIS 10.2, display that the highest concentrations of air pollutants were in the center and north of the study area. The highest concentrations of pollutants were in November and March, whereas lower concentrations observed during January period. The average monthly concentrations of (TSP) measured during the study period was $(504.4 \mu \mathrm{g} / \mathrm{m} 3,359.5 \mu \mathrm{g} / \mathrm{m} 3,32.2 \mu \mathrm{g} / \mathrm{m} 3,324.8 \mu \mathrm{g} / \mathrm{m} 3$, and $392.45 \mu \mathrm{g} / \mathrm{m} 3)$ from November 2015 to March 2016, these results were significantly higher than the permissible allowable limits of the Iraqi national $(350 \mu \mathrm{g} / \mathrm{m} 3)$ and international allowable limits $(150 \mu \mathrm{g} / \mathrm{m} 3)$, except for January is founded (32.2 $\mu \mathrm{g} / \mathrm{m} 3$ ) within the acceptable limits due to heavy rainfall. the averages monthly concentrations of (CO), $(6.567,5.165,4.08,5.454$ and $7.25 \mathrm{ppm})$ were lower than standards limits for five months, comparing with the Iraqi National limits $(35 \mathrm{ppm})$ and WHO Limits $(9 \mathrm{ppm})$. Pollutant concentrations such as $\left(\mathrm{O}_{3}\right)$, were within acceptable limits of Iraqi and WHO limits at all period of study, while other air pollution gasses such as $\left(\mathrm{SO}_{2}\right.$ and $\left.\mathrm{NO}_{2}\right)$, their concentrations over the study area were within the Iraqi national limits but slightly over the WHO limits.
\end{abstract}

\section{Introduction}

Air is essential to all life forms. All depends on its existence; without it, nothing breathes or lives. For these reasons, air quality monitoring should be one of the most important priorities. While recognizing that air quality has such a significant impact on the quality of life, the European Union placed air quality at the top of its thirteen quality of life indicators list [1]. Air is always unclean and always contaminated with gases such as carbon dioxide $\mathrm{CO}_{2}$, nitrogen dioxide $\mathrm{NO}_{2}$, and sulfur dioxide $\mathrm{SO}_{2}$, which can be toxic in nature and divided into solid, liquid and smog particles. Air becomes polluted due to the presence of pollutants mentioned above. The presence of these contaminants in the air called air pollution and the materials, which pollute the air, called air pollutants. In fact, the pollution of air (or atmosphere) is an undesirable change in air quality caused by the emission of gases from the burning of fossil fuels, volcanic eruptions and the discharge of particulate matter into the atmosphere by industrial activities and soil erosion [2].
The impact of air pollution on public health depends on many factors, such as the chemical composition of pollutants, the level of concentration, the presence of other pollutants, the existing health of individuals, and periods of exposure. Other than air pollution, the most likely risk to public health in the present car dominated transport system is road accident deaths and injuries worldwide.

The transport sector is a major contributor to climate change caused by greenhouse emissions. Transportation is one of the basic components in modern human daily life. However, it has both productive effects on human development and detrimental effects on public health. The number of motor vehicles is estimated to be over 800 million worldwide and is increasing almost everywhere at higher rates than human population, and road traffic may be growing even more rapidly. The number of private cars worldwide rose to 500 million in 1990 from 50 million in 1950 [3]. Transport emissions comprise about $20 \%$ of the total greenhouse gas emissions [4]. The transport sector, as an important source of emissions, adds a wide range of gaseous air

\footnotetext{
* Corresponding author: zbm asr@yahoo.com
} 
pollutants and particulate matter of different sizes and compositions to the environment.

In the new global economy, human population has become a central issue. As the population on the earth grows, vehicle and other emissions increase, pollutants, which contain toxic substances such as heavy metals, polycyclic aromatic hydrocarbons (PAH), volatile organic compounds (VOC) and particulates $\left(\mathrm{PM}_{10}\right)$, have an increasing impact on urban air quality. In addition, photochemical reactions resulting from the action of sunlight on nitrogen dioxide $\left(\mathrm{NO}_{2}\right)$ and VOCs from vehicles lead to the formation of ozone. This secondary long-range pollutant sometimes affects population far away from the original emission site. In addition, acid rain is another long-range pollutant caused by vehicle nitrogen oxides and sulfurous emissions, and it could therefore concluded that traffic pollution problems are worsening worldwide [5].

\section{Objectives}

The main objectives of this thesis work are:

1. Monitor and analyze of urban air pollution dispersion in Al-Kut city using ground measurements of some pollutant such as $\left(\mathrm{CO}, \mathrm{NO}_{2}, \mathrm{O}_{3}, \mathrm{SO}_{2}, \mathrm{TSP}, \mathrm{PM}_{2.5}\right.$, and $\left.\mathrm{PM}_{10}\right)$.

2. Investigate the relationship between in site urban air pollutants with land use classes and some metrological factors (temperature, humidity, wind speed).

\section{Study area}

Al-Kut is an Iraqi city located on the banks of the Tigris River, which is the administrative center of the Wasit province of Iraq. Which it built by Al-Hajjaj ibn Yusuf Althaqafy at $78 \mathrm{AH}$ and completed in $86 \mathrm{AH}$. Kut, is a city with distinct features are on a peninsula shape surrounded by the Tigris River from the east, west and south sides, and containing Kut Barrage built by the city's sons under the supervision of the English in the first half of the twentieth century (1938), which divided them rivers of Dujail and Garraf, as well as containing AlKarama bridge which was built in the era leader Abdul Karim Kassem, founder of the Republic of Iraq in 1958. The well-known sites in the city: the textile factory and Alhorh Street, Almasaif hotel, and the University of Wasit, which is one of the most important landmarks in the city as shown in Figure. 1.

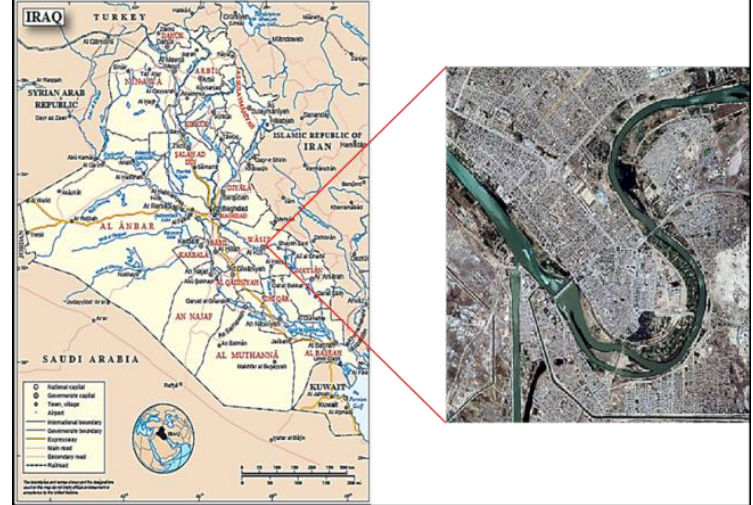

Fig.1. Map of Iraq showing the location of Al-Kut city.

\section{Methodology and sampling}

In this study, 20 deferent site locations has been selected to monitoring the concentrations of air pollutants. The distribution of selected sites was to cover nearly all the area of AL_Kut city center, including the mainly crowded intersections and different land classifications (residential, commercial, vegetation, barren and industrial areas). Figure (2) shows AL Kut map with samples location. The measurement of concentrations has been done by using different devices to monitoring the concentrations of air pollutants such as (AEROCET 531, GIG450 devices, NOVA600 devices, MiniRAE 3000, Eco Sensors UV-100) as shown in Figure (3) below, Which measure (TSP, $\mathrm{PM}_{1}, \mathrm{PM}_{2.5}, \mathrm{PM}_{7}, \mathrm{PM}_{10}$, $\mathrm{CO}, \mathrm{NO}_{2}, \mathrm{SO}_{2}, \mathrm{O}_{3}$ ). The site locations were located by using Garmin GPS72. The measuring period was five months starting from November (2015) to March (2016).

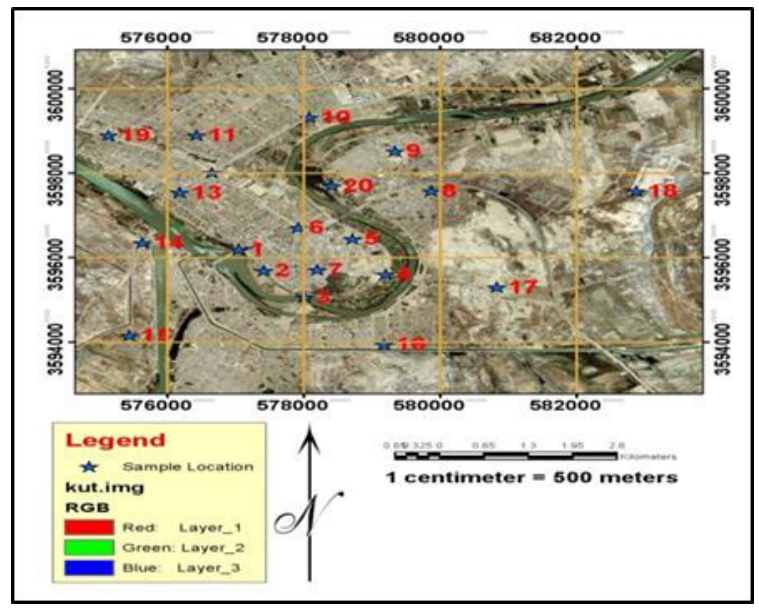

Fig. 2. Map of AL_Kut city with sample locations. 


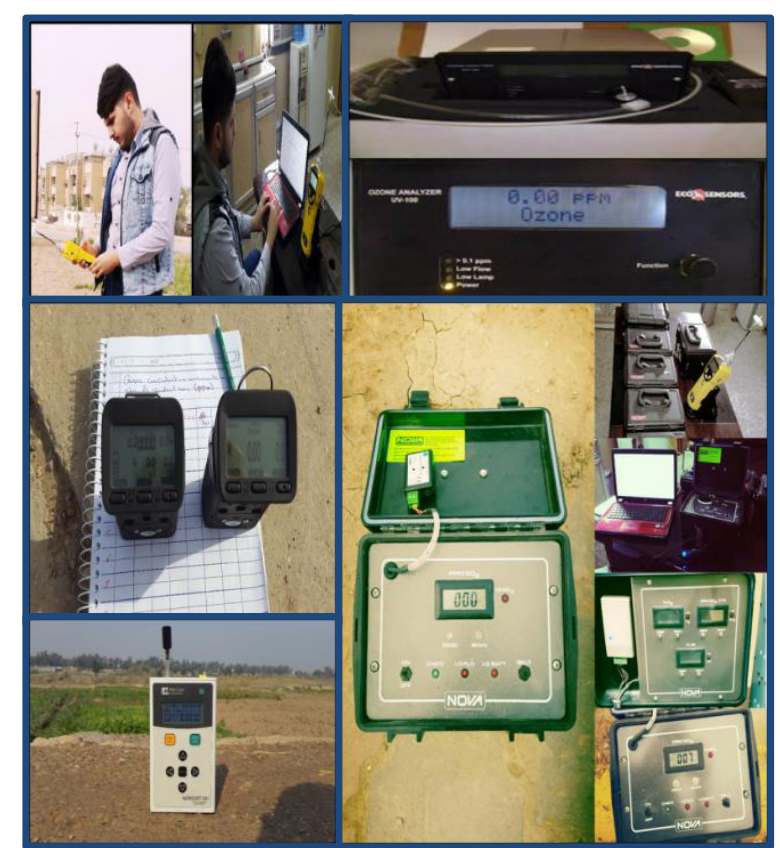

Fig. 3. Some devices that use to measuring air pollutants during the study period.

\section{Results}

The results of this study were including two parts: the first one deals with air pollutants (TSP, PMs, $\mathrm{CO}, \mathrm{NO}_{2}$, $\mathrm{SO}_{2}, \mathrm{O}_{3}$ ) for five months starting from November 2015 to March 2016 and the analysis of their results. Secondly, express the relationship between land use and air pollution.

\subsection{Total suspended particulate (TSP)}

Total suspended particulate data from (20) locations were imported to geographical information system to drive TSP dispersion maps for the center of AL-Kut city as shown in Figure (4) below. This figure show that concentration of total suspended particulate pollutants is higher than the permissible limits of the Iraqi National limits $(350 \mu \mathrm{g} / \mathrm{m} 3)$ and the world limits $(150 \mu \mathrm{g} / \mathrm{m} 3)$, which are mostly in traffics intersections.

Very high concentration of TSP in most of the sites and along the study period was due to several causes, such as very high traffic congestion in these sites, the uncleaned streets specially streets shoulders which filled with dust, in addition to wind that led to blowing dust from streets to the air. Excluding the period during January 2016, where the concentrations of TSP was at minimum values and within the permissible limits of Iraqi and international standards because of the rains almost continuously during this month. Which led to reduce concentration of TSP from air and stabling on the ground. The great difference between the periods reflects the great effect of the seasonal changes specially rains and temperature. Figure (5) below shows some of the intersections and the uncleaned streets that filled with dust and causes high concentration of TSP in most of the study area.

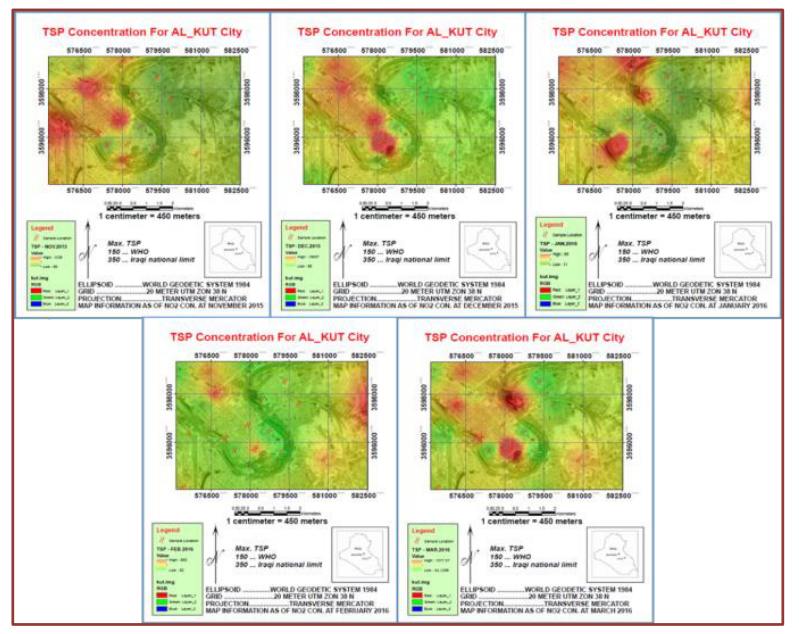

Fig. 4. Distribution of TSP concentration over AL-Kut city from November 2015 to March 2016.

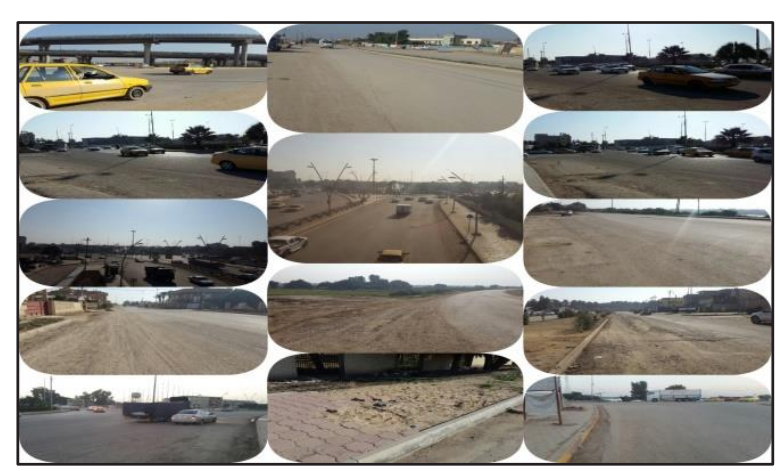

Fig. 5. Some intersections and streets of the study area.

\subsection{Particulate matter (PMs)}

Figures (6) demonstrate the sites which has high concentrations of PMs was the same sites of high concentrations of TSP, that means both of them have the same causes and sources. Which means that PM2.5 and PM10 were results due to traffic intensity, uncleaned streets that filled with dust, furthermore winds that led to blowing dust from streets to the air.

By using geomatics technique (remote sensing then identifying areas of influence by using GIS is proved to be a good efficiency in the quick identification of contaminants and prepared it for environmental decision maker. There are a lot of gasses that influence in the climate change but here we discussed the most important gasses influence on the change in climate. The values of climate change gasses $(\mathrm{CO} 2, \mathrm{~N} 2 \mathrm{O}$, and $\mathrm{CH} 4)$ that have been calculated from the formula of emission have different value according to the quantity of fuel used in each brick factory. Where the value of $\mathrm{CO} 2$ ranged from (695 -854 tones), value of $\mathrm{N} 2 \mathrm{O}$ ranged from (1.905 2.318 tones), and finally value of $\mathrm{CH} 4$ ranged from (0.286 -0.347 tones). 


\subsection{Carbon monoxide (CO)}

From a filed measurement in the study area, it has been found that the highest concentrations of $\mathrm{CO}$ was in the north of city at locations No. (10, 11, and 12) during the study period (five months) as shown in Figure (7) below. The concentrations of these locations were high but within acceptable limits of Iraqi standards that is (35 ppm) and exceeding international standards, which is (9 ppm). Other sites were within acceptable standards ranging between $(0.15 \mathrm{ppm}-12 \mathrm{ppm})$.

The high values for $\mathrm{CO}$ in the north of city were due to the intersections with huge numbers of vehicles furthermore the using of bad-quality benzene by the vehicles that led to incomplete combustion, which generates carbon monoxide gas instead of carbon dioxide gas.

The concentration of $\mathrm{CO}$ gradually increased with increasing air temperature as shown in all sites. For example CO concentration was (22 ppm) in November 2015 which decrease to become (16 ppm) in January 2016 due to the decreasing in air temperature and gradually increased to be ( $25 \mathrm{ppm})$ in March 2016 due to the increasing temperature in this month.

Highest values of CO were recorded in location (No.11) with values ( 25 ppm and 22 ppm) during March 2016 and November 2015 sequentially and that was due to the heavy traffic and locate near a garage and petrol station. In December and January, as shown in Figures (7), the minimum concentration was (0.11 ppm) in (No.20) which located in west-north of the city and conceder as agriculture area with low traffic volume.
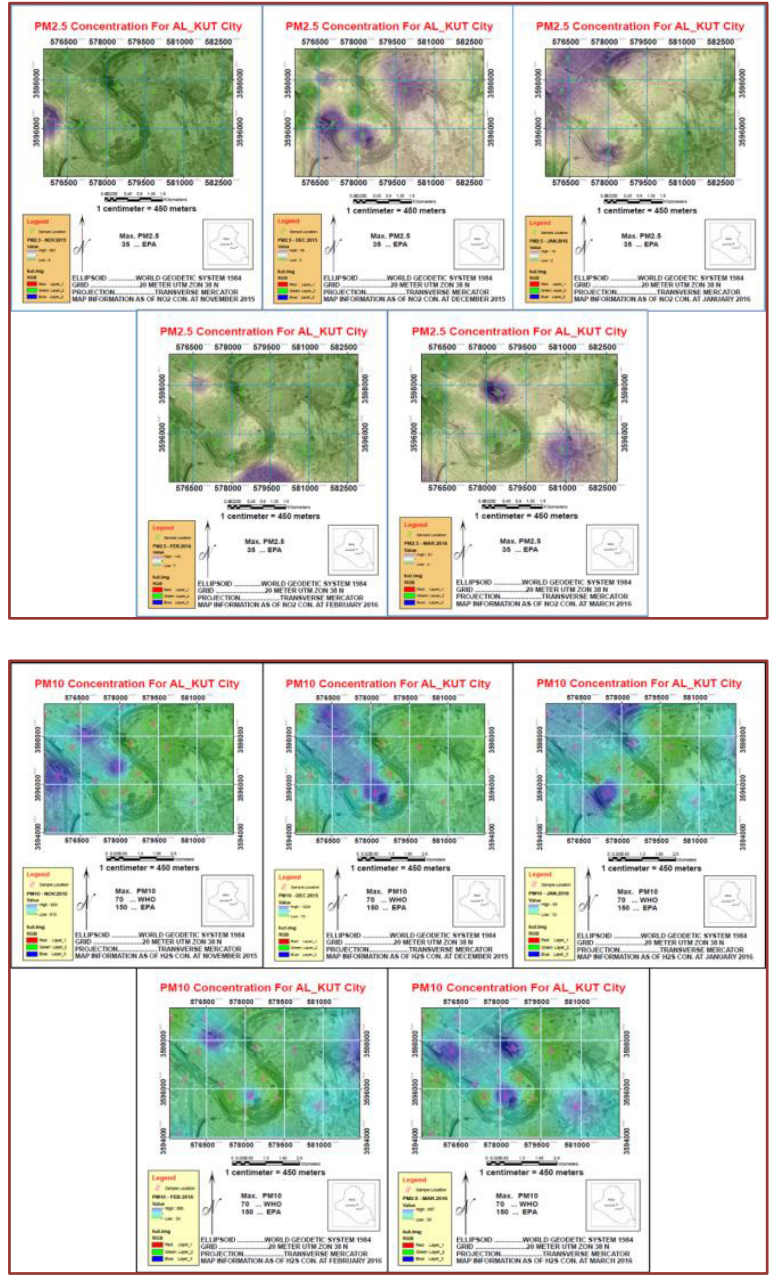

Fig. 6. Distribution of PMs concentration over AL-Kut city from November 2015 to March 2016.

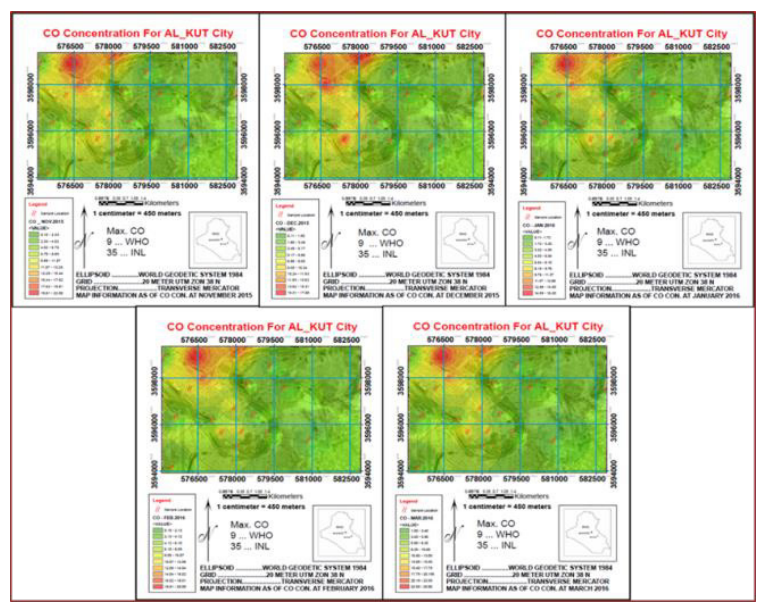

Fig. 7. Distribution of Co concentration over AL-Kut city from November 2015 to March 2016.

\subsection{Nitrogen dioxide $\left(\mathrm{NO}_{2}\right)$}

Figure (8) shown below describes the distribution of NO2 in the air of AL-Kut city. It obvious that, for mostly locations and during all period that the concentration of NO2 was within the Iraqi national limits which is about 
(0.25 ppm). Expect one location was slightly exceeding the limits by $(0.01 \mathrm{ppm}-0.02 \mathrm{ppm})$, that location was (No.11) with concentration of ( $0.26 \mathrm{ppm})$ at November 2015 and $(0.27 \mathrm{ppm})$ at March 2016.

The maximum concentration of NO2 was in site (No.11) with value of $(0.27 \mathrm{ppm})$ at March 2016 , While the minimum value was reached to $(0.01 \mathrm{ppm})$ in many locations through several months.

Graphically, It can noticed that in November 2015, the maximum value of NO2 was $(0.26 \mathrm{ppm})$ which detected in site (No.11), while the minimum value was $(0.01 \mathrm{ppm})$ in site (No.16). In the next two month, the values were gradually decrease in the most of the sites. While February and march gradually increase in concentrations for all locations of the study area.

The rise in NO2 concentrations in major intersections of the city was due to heavy traffic jam that led to emitted high quantities of NO2 into the air as shown in the north and middle of city. Which represented by locations No. $(6,7,10,11$, and 12).

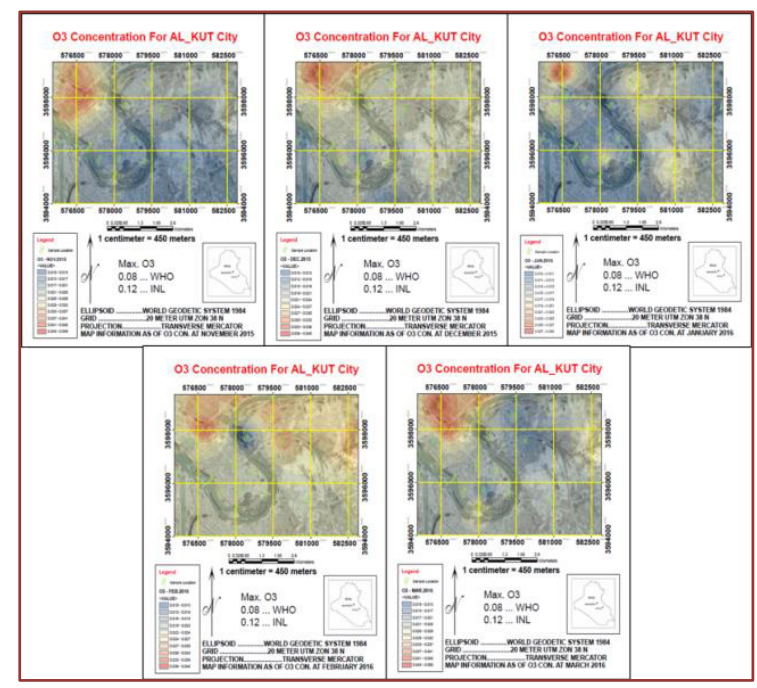

Fig. 8. Distribution of No2 concentration over AL-Kut city from November 2015 to March 2016.

\subsection{Ozone $\left(\mathrm{O}_{3}\right)$}

Ozone (O3) measured several times in (20) different sites distributed in the study area aiming to understand the sources and causes of this gas as shown in Figure (9). In general, the measurement showed that the concentrations of $\mathrm{O} 3$ not exceeded the international and Iraqi standard limits, which are $(0.08 \mathrm{ppm})$, and $(0.12 \mathrm{ppm})$ sequentially. During the period November 2015 to March 2016, the maximum values of O3 were in site (No.12) measured in November and March with values reached to $(0.05 \mathrm{ppm})$. In addition, site (No.11) measured in March where the concentrations reached to $(0.05 \mathrm{ppm})$. While the minimum value of ozone gas was $(0.01 \mathrm{ppm})$ in many locations through different periods.

In November, the highest reading of $\mathrm{O} 3$ was recorded to be $(0.05 \mathrm{ppm})$ that demonstrated the city is not polluted by Ozone because all readings were below the acceptable Standard limit, which is $(0.08 \mathrm{ppm})$. In the next month, the concentration of $\mathrm{O} 3$ declined slightly in all sites of the study area. However, the lowest values of ozone recorded in January due to the decrease in air temperature during this month. While the next two months witnessed gradually rise in concentrations.

Finally, it can be notice that the major reasons of $\mathrm{O} 3$ formation is that sunlight causes photochemical reactions involving NOx and VOCs. Therefore, high O3 concentrations founded in a crowded intersections in the north of the study area due to high concentrations of NO2 and VOCs.

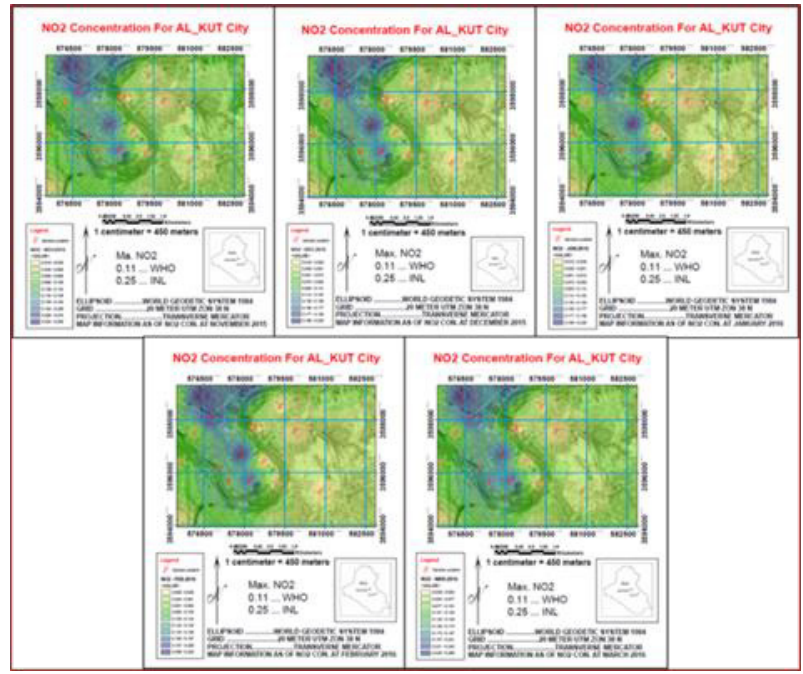

Fig. 9. Distribution of $\mathrm{O} 3$ concentration over AL-Kut city from November 2015 to March 2016

\subsection{Sulfur dioxide $\left(\mathrm{SO}_{2}\right)$}

Broadly, the SO2 concentrations were within the Iraqi standard limits in almost locations for the city. Figure (10) shows one location was exceeded the standard limit $(0.14 \mathrm{ppm})$, during the study period; this location is (No.12) were concentrations ranged between $(0.2 \mathrm{ppm})$ to $(0.25 \mathrm{ppm})$ due to high traffic volume that led to significant quantities of $\mathrm{SO} 2$ through vehicles exhausts according the process of fuel combustion. Additionally, it is located adjacent to a textile factory, garage, and a petrol station.

In November, the minimum concentrations were $(0.11$ ppm) that recorded in (No.4, No.14 and No.19) which locates in the south of city. On the other hand, the maximum value found in the location of (No.12) with a value of $(0.22 \mathrm{ppm})$. While the remaining sites, there concentrations ranging between $(0.02 \mathrm{ppm})$ to $(0.14$ $\mathrm{ppm})$. The concentrations of SO2 were slightly inclined in December and January in all locations. The next two months which represented by February and March witnessed gradually increased in SO2 concentrations. 
Finally, it can be notice that the concentration of $\mathrm{SO} 2$ spreads widely in areas that crowded by cars and neighboring industrial areas specifically in the north of the study area.

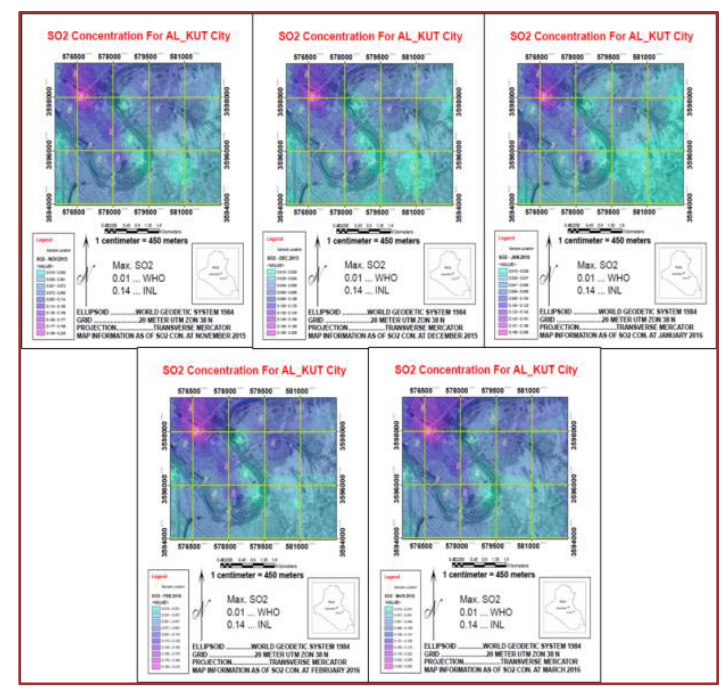

Fig. 10. Distribution of $\mathrm{SO} 2$ concentration over AL-Kut city from November 2015 to March 2016

\subsection{Land use relationship with air pollution}

Urban areas are associated with sources of a variety of air pollutants, and regional pollution problems such as acid rain and photochemical smog. Cities are also major contributors to global air pollution related to ozone depletion and carbon dioxide (CO2) warming. Within an urban area, the level of pollution varies with the distance to pollution sources, including both stationary and mobile sources (e.g., vehicles).

Land use and land cover changes due to urbanization impact and effect on air quality in the city are important. The impacts of land use predicted to have substantial impacts on gases emissions and directly effects on the urban environment. Therefore, land use of the studied area was investigate and studied with the gases concentration patterns. Figure (11) shows the land use of AL-Kut city with samples locations. By comparing the land use map with the gases concentrations, it can noticed that approximately all gases concentrations were widely distributed in urban areas and nearly to industrial areas especially in the north and middle of the city. Locations $(10,11,12,6$ and 7$)$ have the maximum values during the study period. On the other hand, the minimum concentrations were widely distributed near the vegetation and barren areas. Finally, the land use impacts on the TSP and PMs founded in the barren and urban areas especially in the intersections and roads of the city. The TSP and PMs Distribution were widely founded in stations of $(6,7,10,11,12$ and 18).

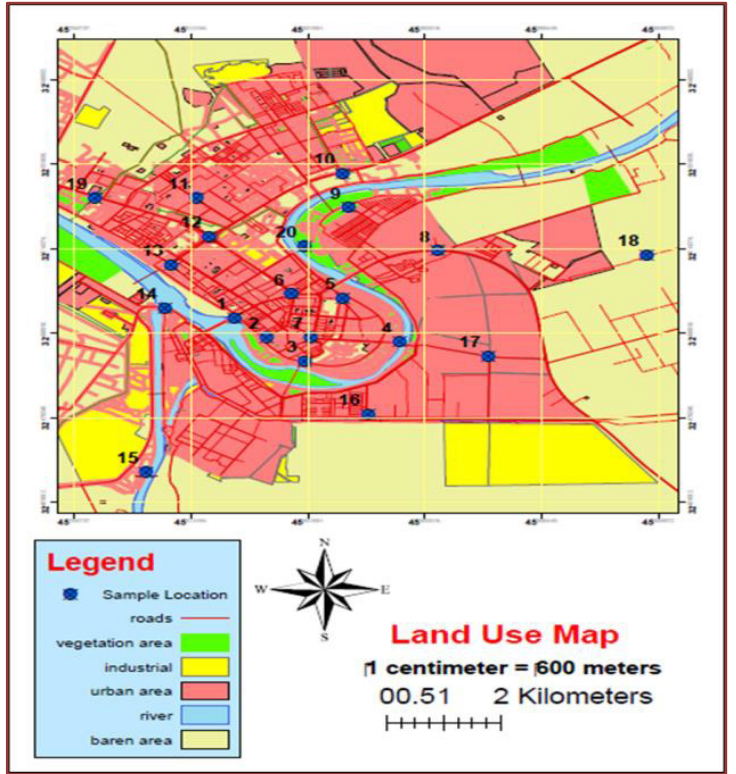

Fig. 11. Land Use map classification with sample locations

\section{Conclusions}

1. Arc GIS analysis distribution of air pollution maps showed that the highest concentration of pollutants were in the center and north of the city, where important intersections with heavy traffic volume and petrol stations are locate, and near to the industrial areas.

2. TSP and PM concentrations of AL-Kut city during (November, December, February, and March) were higher than Iraqi standards, while during January were within acceptable standards. The TSP concentrations were high in those locations due to high traffic volume and due to Non-regular; streets filled with dust that volatile on the air because of vehicles movement and wind gusts.

3. In terms of gases, the research showed that $\mathrm{CO}$, and O3 concentrations were not exceeded the Iraqi standards. However, in the north of city, a high concentration had detected, the reason was due to the heavy traffic of the area.

4. $\mathrm{NO} 2$ and $\mathrm{SO} 2$ concentrations were higher than the allowable limits during March 2016 in north of ALKut city. The increment of concentrations found to be due to the fuel combustion by vehicles.

5. Anthropogenic sources affecting on the city's air pollution through a variety of plants and factories that surround the city from all destinations, along with the presence of more than an industrial area in the center and north of the city and near the residential neighborhoods that content of laboratories and industrial workshops.

6. The exhausts in all forms of transportation affecting on the city's air pollution. which has increased their numbers in recent years as a result of improved living conditions and the economic level of the city's people, with the survival of a large collection of old vehicle with damaged motors that operating on the 
emission of black smoke into the air without censorship and sense of responsibility.

\section{References}

1. Tulloch, M. and Li Jonathan, 2004, Environmental Information Archives, Volume 2 (2004), 846-854.

2. Ahluwalia, V.K., Malhotra, S., Environmental Science, a book, Pvt. Ltd. Goalie Enterprises, India, (2006).

3. Kamerman, S. B. and OECD, Social policies, family types and child outcomes in selected OECD countries. Organization for Economic Cooperation and Development. Employment, Labor and Social Affairs Committee (2003).

4. Beer, T., Grant, T., Williams, D. and Watson, H, Atmospheric Environment, 36, (4), pp. 753763, (2002).

5. Leksmono, N. S., Longhurst, J. W. S., Ling, K. A., Chatterton, T. J., Fisher, B. E. A., Irwin, J. G.:a theoretical modelling exercise, Environmental Modelling \& Software, 21, (4), pp. 494-500. (2006). 